\title{
Pronominal Subjects in English L2 Acquisition and in L1 Greek: Issues of Interpretation, Use and L1 Transfer
}

\author{
Alexandra Prentza \\ Aristotle University of Thessaloniki \\ prentzal@gmail.com
}

\begin{abstract}
This study examines the L2 acquisition of English pronominal subjects by Greek learners and its possible causes. It also considers the factors that affect pronoun resolution in L1 Greek. Null pronominal subjects were found to be used even by advanced learners, especially in topic-continuity contexts. This is attributed to the transfer of the L1 property of null subjects and to the interpretive effects thereby achieved. Regarding pronoun resolution in Greek, we found that the syntactic constraint related to the null/overt realization of pronominal subjects is such a decisive factor that its effect surfaces even when antecedents are pragmatically inferred.
\end{abstract}

\section{Theoretical Background}

\subsection{Introduction}

Optionality in phenomena at the syntax-discourse interface has been the focus of much recent research. L2 inconsistent performance has been accounted for in two ways: narrow syntax vs. the interfaces. Interface Vulnerability Hypotheses (Hulk \& Muller 2000; Sorace \& Filiaci 2006; Belletti et al. 2007; Sorace \& Serratrice 2009) maintain that formal features are acquirable in $L 2$ acquisition but the interfaces and the related interpretable features are not. This implies that cross-linguistic influence may not be relevant to any learnability problems. On the other hand, Formal Features Deficit Accounts (Smith \& Tsimpli 1995; Hawkins \& Hattori 2006) like the Interpretability Hypothesis (Tsimpli \& Dimitrakopoulou 2007) attribute L2 variability to a deficit in uninterpretable features which are

(cc) BY-NC-ND 
assumed to remain inaccessible, unlike interpretable features that are more readily available. Here, the implication is that $L 1$ transfer may be associated with L2 instability.

Previous L2 findings on pronoun interpretation have reported residual optionality manifested in two ways: first, learners were found to overuse overt pronominal subjects in topic-maintenance contexts (Bini 1993; Pérez-Leroux \& Glass 1999; Margaza \& Bel 2006; Sorace \& Filiaci 2006; Belletti et al. 2007; Lozano 2008) and, second, to a much lesser extent, they inaccurately used null pronominal subjects in topic-shift contexts (Monrtul \& Louro 2006; Lozano 2008, 2009; Jegerski, et al. 2011). By contrast, concerning production, some studies have reported that speakers of non null-subject languages (NNSLs) learning a null-subject language (NSL) produce null pronominal subjects at rates comparable to those of native speakers (Liceras Diaz \& Maxwell 1999; Belletti et al. 2007).

Studies on pronoun resolution in Greek have shown that speakers interpret null subject pronouns as anaphoric to the first-clause subject and overt subject pronouns as anaphoric to the first-clause object (Dimitriadis 1996; Tsimpli et al. 2003, 2004; Miltsakaki 2007; Papadopoulou et al. 2007). Similar findings have also been reported for other NSLs (Carminati 2002, 2005 for Italian, Mayol 2008; Jegerski, et al. 2011 for Spanish)1. For this study, a replication of such approaches is important for two reasons: first, it can show that syntactic issues are fundamental to the resolution of pronominal ambiguity in Greek and second, it will provide strong evidence that null pronoun use in L2 English reflects the transfer of the L1 property of subject drop in topic-continuity contexts.

\subsection{Pronominal Subjects: Licensing and Distribution}

It is well known that NSLs like Greek feature null lexical and pronominal subjects in matrix and subordinate clauses, a possibility not available for English, as (1) demonstrates:

(1)
pro ipe
oti pro tha mas tilefonisi
Said.3SG that will us call.3SG
*Said that will call us
'He/She said that he/she will call us'

1 However, other studies have shown that overt subject pronouns have a more flexible procedure of antecedent assignment (Alonso-Ovalle et al. 2002; Geber 2006; Meridor, 2006). The discussion of this issue is beyond the scope of this paper. 
Within minimalism these differences have been accounted for as differences in the way the uninterpretable phi-features of $T$ is valued. In English the phifeatures of $T$ are valued by Move/Merge of an overt subject/expletive in the Spec,TP. Conversely, in Greek, the valuation proceeds through verbal agreement morphology, which is assumed to be nominal in nature. Therefore, the SpecTP/ IP position need not be occupied by an overt subject (Barbosa 1995, 2009; Alexiadou \& Anagnostopoulou 1998; Spyropoulos \& Philippaki-Warburton 2001; Roussou \& Tsimpli 2006). According to minimalist assumptions on crosslinguistic variation (Chomsky 1995, 2001), this difference between Greek and English amounts to a divergence in the feature specification of the functional head(s) associated with subject-verb agreement or, in other words, to a difference with uninterpretable features.

The distribution of null and overt subjects in NSLs is assumed to be regulated by the interpretable [topic-shift] feature: null pronouns denote topic-maintenance while overt pronouns topic-shift (Cardinaletti \& Starke 2001; Carminati 2002; Tsimpli et al. 2003, 2004). In English overt pronouns are obligatory and thus discursively unmarked. See (2-4):

(2) -Milise 0 Janis stin Anna?

Talked.3SG the.NOM Janis.NOM to.ACC Anna.ACC?

'Did Janis talk to Anna?'

(3a) -Ne, pro tis milise yes, pro her talked.3SG

(3b) -??Ne, aftos tis milise yes, he.NOM her talked.3SG

(topic-continuity) Did John talk to Anna? -Yes, he did (a\&b)

In NSLs, subject pronoun interpretation with competing antecedents has been argued to depend on the null/overt realization of the pronoun to be referenced: whereas for null pronouns the preferred antecedent is in subject position, for overt pronouns it is in object position (Carminati 2002 for Italian, Tsimpli et al. 2004; Miltsakaki 2007; Papadopoulou et al., 2007 for Greek). See (5):

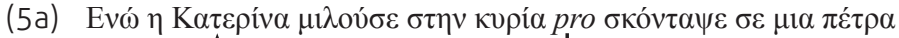

\section{4}

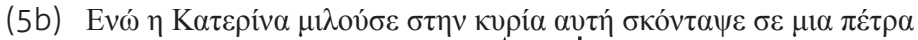

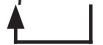

(5c) While Katerina-i was talking to the lady $\mathrm{s}_{\mathrm{k}^{\prime}}$ pro $_{-i} / \mathrm{she}_{-\mathrm{k}}$ tripped over a stone

Besides the factor of Pronoun Type (PT) (null/overt realization of pronominal subject), which is related to the exploitation of a parametric option available in 
Greek, our study considers the variable of World Knowledge Inference (WKI), i.e. whether the choice of an antecedent is inferred based on world knowledge or not. Our aim was to explore how Greek speakers resolve the ambiguity in contexts where both variables are incorporated; whether they proceed based on syntax and the interpretive distinctions encoded by parametric choices or based on the pragmatics of a sentence and the reference assignment thereby dictated.

Endorsing the view that uninterpretable features are related to prolonged acquisitional problems, we predict that in the English tests i) Greek learners will accept/produce null pronominal subjects even in advanced stages of proficiency and ii) Greek learners but not the English natives will accept/produce more null pronominal subjects when these refer to the first-clause ${ }^{2}$ subject than when they are referentially disjoint from it transferring an L1 property. In the Greek pronoun resolution test we expect speakers to assign null pronouns to subject antecedents and overt pronouns to object antecedents.

\section{The Experiment}

\subsection{Subjects and Materials}

Seventy-two Greek learners and a control group of twenty-five English native speakers (NS) took the English tests while sixty-seven Greek speakers took the Greek test. The Greek learners of the first experiment were tested by the Oxford Quick Placement Test (2001) and divided into thirty-five intermediate (INT) and thirty-seven advanced (ADV) learners. They were administered one judgement and two production tasks: a Paced Grammaticality Judgement Task (PGJT), a Sentence Completion Task (SCT) and a Cloze Test (CT).

The PGJT aimed to test the acceptability of null and overt pronominal subjects in English subordinate clauses. It consisted of ten items in which the subject pronoun referred to the first-clause subject (Coreferential condition, henceforth, CoR) and of ten items in which the subject pronoun was referentially disjoint from it (Disjoint Reference condition, henceforth, DjR). This categorization is related to the Pronoun Reference Type (PRT) variable. In each type, half of the items were ungrammatical, while the other half were grammatical. Sentences in

2 We use this term because the linearly first clause is either matrix or subordinate in the tasks used. 
(6) provide examples:

(6a) *We won't finish on time if pro don't start now Mary was angry because she had lost her job.

(6b) *It is so hot in here that pro sweat all the time The movie was so boring that Mary fell asleep.

Participants had to indicate their judgements using a -2 to +2 scale as follows: -2 would be given to an ungrammatical sentence, +2 to a grammatical sentence and $O$ if they thought that a sentence had equal chances of being grammatical or ungrammatical. Zero responses were not eliminated in the statistical analysis since it was decided that in this study uncertainty in judgement would be exploited. Participants were also given choices -1 and +1 . They ought to use them when they were not as sure about the (un)grammaticality of a sentence as they were when they used the extremes of the scale. For reasons of presentation, during data inputting this scale was matched to a 1-5 scale. In this way, for both grammatical and ungrammatical items the scale categories encoded the same choices regarding accuracy and certainty in judgement. See (7):

(7) 5: accurate-categorical (-2 for ungram., +2 gram.)

4: accurate-non-categorical (-1 for ungram., +1 for gram.)

3: inaccurate (0 for ungram./ gram.)

2: inaccurate-non-categorical (+1 for ungram., -1 for gram.)

1: inaccurate-categorical (+2 for ungram., -2 for gram.)

The subjects read on a screen and at the same time listened to the test items. Each item had to be judged during a 5-second gap.

The SCT tested the production of null and overt subject pronouns. It consisted of sixteen items in which the targeted pronoun referred to the first-clause subject and of sixteen items in which it did not. Participants had to conjoin the sets of clauses presented to them. Only the predicate of the second clause was given. See (8) (anticipated responses in italics):

(8a) When she heard the news [tell/ all friends] When she heard the news she told all her friends

(8b) We can't pay you because [you/ not complete/ the work] We can't pay you because you haven't completed the work yet

Performance was analyzed in terms of target and non-target responses which were related to pronominal subject use and omission respectively.

The CT also tested the production of null and overt pronominal subjects, yet in a less restricted context. Participants were given ten short passages including 
fourteen test items and sixty-two fillers. In eight of the test items the targeted response was a pronoun coreferential with the first-clause subject while in the remaining six the pronoun was disjoint in reference. See (9) (anticipated response in italics):

(9a) They hold one's interest...., because ...... they ........ are carefully written.

(9b) Hunters sell .....their....skin because ... it .... is very expensive'

Target and non-target responses corresponded to overt pronominal subject production vs. omission respectively.

In the Greek test participants had to indicate the antecedent of the pronominal subject of the second clause choosing from a set of three options: the firstclause $^{3}$ subject, the first-clause object or either. The test consisted of fifteen items in which the response was not pragmatically biased and of sixteen items in which it was. This categorization is associated with the variable of WKI (-/+ WKI). In half of the +WKI items the felicitous response was the subject, whereas in the other half it was the object. Moreover, in 8 items of the +WKI type and in eight items of the -WKI type the pronoun to be referenced was overt, while in the remaining items in both types the pronoun was null. This distinction is related to the variable of Pronoun Type (PT). Sentences in (10) exemplify -WKI items. Sentences in (11) and (12) illustrate +WKI items:

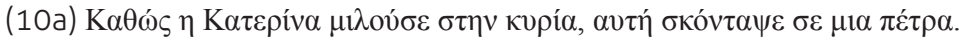
While Katerina was talking to the lady, she tripped over a stone

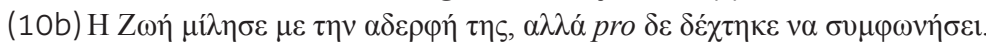
*Zoe talked to her sister but pro didn't agree to consent

\section{Subject Biased Items}

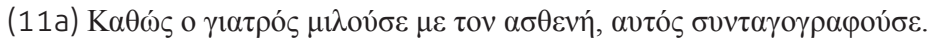

While the doctor was talking to the patient, he was making up the prescription

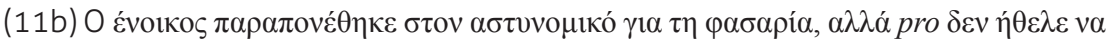

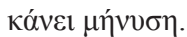

*The tenant complained to the policeman about the noise but pro didn't want to press any charges

3 All items were instances of forward anaphora, but the linearly first clause could be either matrix or subordinate. 


\section{Object Biased Items}

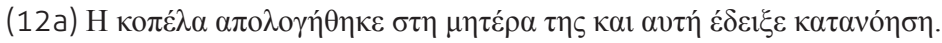
The girl apologized to her mother and she was understanding

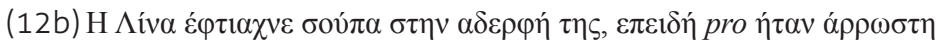
*Lina was cooking soup for her sister because pro was sick

The statistical analysis was conducted as follows: for the PGJT, a random effects factorial GLM (ANOVA) approach was used to assess factors with a significant effect. This approach contributed to accounting for repeated responses. Tukey HSD post-hoc tests were conducted to test for between and within-group differences. For the SCT and the CT, analyses of main effects and interactions were performed through a logistic regression model. In the Greek test, chisquare tests were applied to test for independence between the variables involved. Multinomial logistic regression analyses were applied in order to detect significant differences on the response

\subsection{Results}

\subsubsection{PGJT}

Multiple $3 \times 2 \times 2$ analyses yielded a highly significant main effect of Group ( $F_{2,376}$ $=114.98, p<0.001)$ and Grammaticality $\left(F_{1,376}=143.01, p<0.001\right)$, as well as a main effect of PRT $\left(F_{1,376}=13.32, p<0.05\right)$. Group was found to interact with Grammaticality in a highly significant way $\left(F_{1,376}=47.44, p<0.001\right)$ and with PRT in a significant way $\left(F_{2,376}=4.17, p<0.05\right)$. The interaction of Group $x$ PRT $\times$ Grammaticality was not significant $\left(F_{2,376}=1.47, p>0.05\right)$. Figure 1 illustrates group overall accuracy rates:

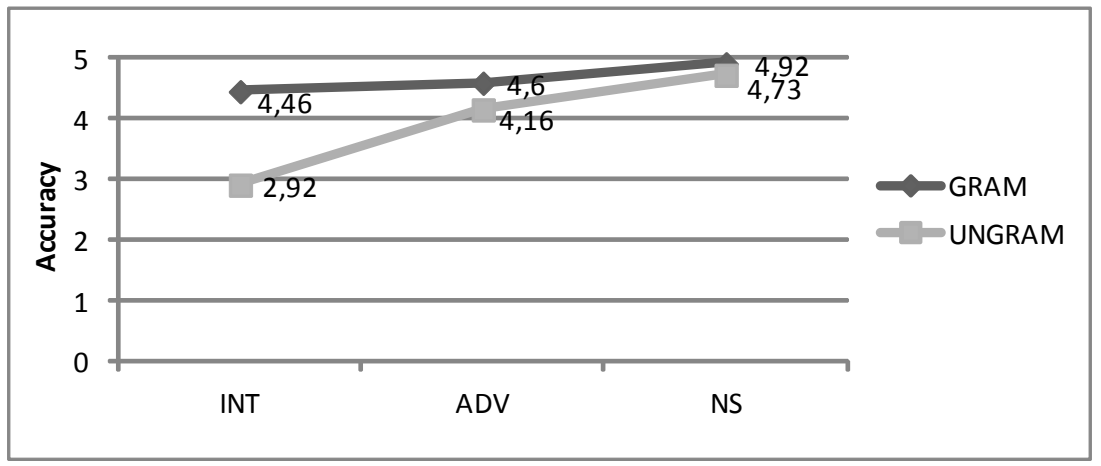

Figure 1. Overall Accuracy Rates 
Within-group comparisons showed a grammaticality effect but only for L2 groups (INT, ADV: $p<0.001, N S: p>0.05$ ). Between-group comparisons in the ungrammatical sentences revealed that all groups differ significantly from one another (INT vs. NS, INT vs. ADV, ADV vs. NS: $p<0.001$ ). In the grammatical sentences the INT and the ADV were significantly less accurate than the NS (INT vs. NS: $p<0.001$, ADV vs. NS: $p<0.05$ ) but no differences were found between the two L2 groups (INT vs. ADV: $p>0.05$ ). The scores in the ungrammatical items were further analyzed by the variable of PRT ${ }^{4}$ and are presented in Figure 2.

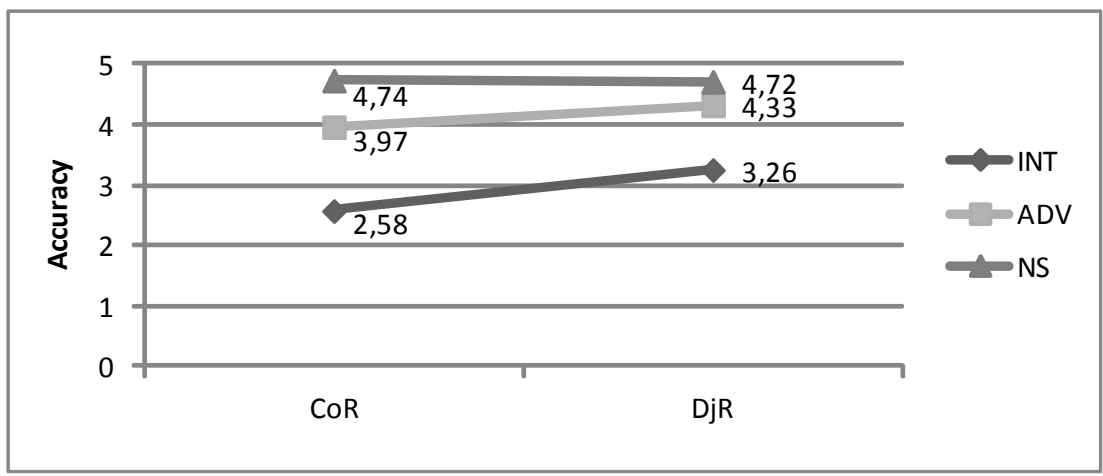

Figure 2. Rejection Scores of null CoR vs. null DjR items

Within-group comparisons revealed that the INT were significantly more accurate in rejecting null pronoun items of the disjoint than of the coreferential type $(p<0.001)$. The ADV rejected more readily ungrammatical disjoint than ungrammatical coreferential items but this difference did not reach significance $(p>0.05)$. Native performance did not differ in the two conditions. As for between-group comparisons, all groups differed from one another in the coreferential condition, and, crucially the ADV from the NS, as predicted (INT vs. NS, INT vs. ADV, ADV vs. NS: all ps < 0.001). In the disjoint condition, as anticipated, there is an improvement since, although the INT are significantly less accurate than the controls $(p<0.001)$, the ADV perform native-like $(p>0.05)$.

4 We are allowed to do so, since the interactions between Group and Grammaticality and Group and PRT were significant. 


\subsubsection{SCT}

A logistic regression analysis returned a main effect of Group in both reference conditions (CoR: Wald test $=53.333, p<0.001$, DjR: Wald test $=21.230, p$ $<0.001$ ). This was further explored through between-group comparisons on pronominal subject use rates organized by reference type (see Figure 3):

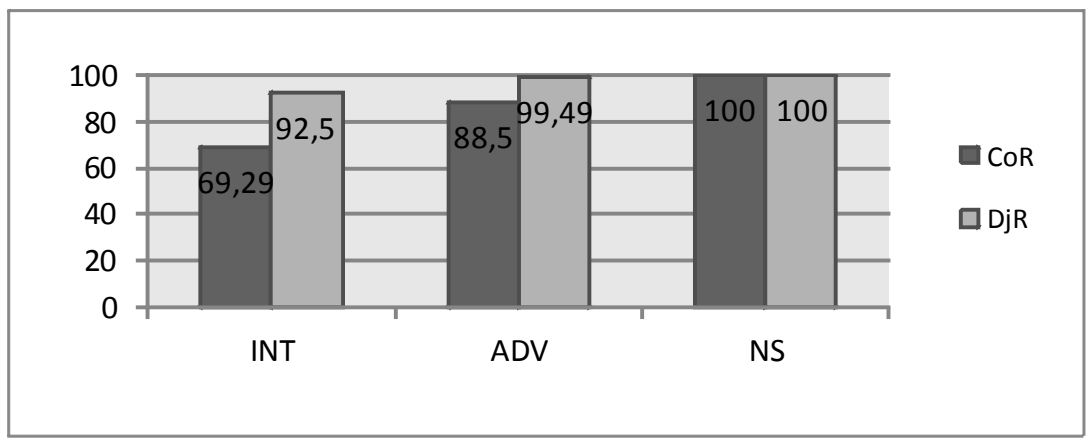

Figure 3. Pronominal Subject Use: CoR vs. DjR

In the coreferential condition there were across group differences. As predicted, the ADV produced significantly fewer overt subject pronouns than the NS group (all $p s<0.01$ ). By contrast, in the disjoint condition, the ADV were as accurate as the controls exhibiting improved performance (INT vs. ADV: $p<0.05$, INT vs. NS: $p$ $<0.01$, ADV vs. NS: $p>0.05$ ). Additional comparisons between coreferential and disjoint items in each group revealed that the INT and, crucially, the ADV produce more null pronominal subjects when these refer to the first-clause subject than when they are referentially disjoint from it, as anticipated (both $p s<0.0001$ ). No similar difference was detected in the NS group $(p>0.05)$.

\subsubsection{CT}

The logistic regression analysis indicated a highly significant main effect of Group (Wald test $=77.200, p<0.001$ ) and a main effect of PRT (Wald test $=$ 19.152, $p<0.01$ ). However, no significant interaction was detected between Group and PRT (Wald test $=0.323, p>0.05$ ). Figure 4 demonstrates overall pronominal subject use rates.

The INT group produced null subject pronouns at a significantly higher rate than the ADV $(p<0.001)$ and the NS group $(p<0.001)$. As predicted, the ADV also performed significantly less accurately than the NS group $(p<0.05)$. Next, group performance was organized by PRT. See Figure 5: 


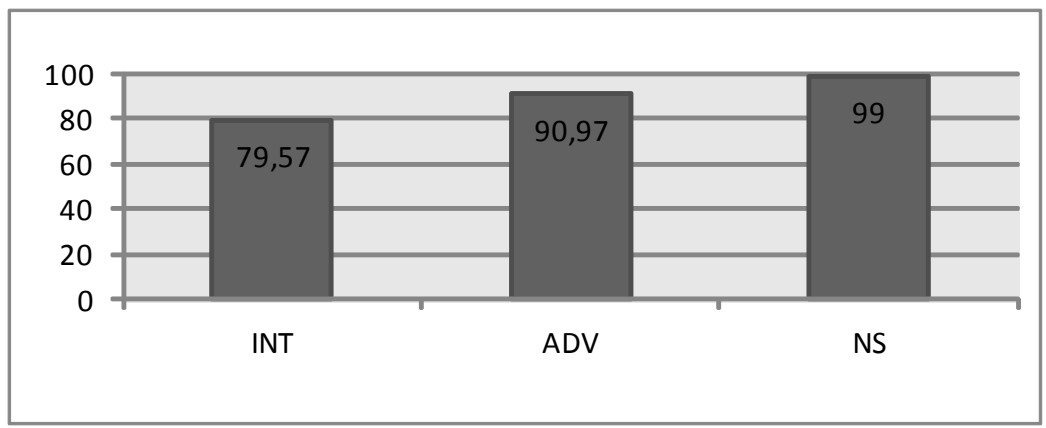

Figure 4. Pronominal Subject Use Overall Scores

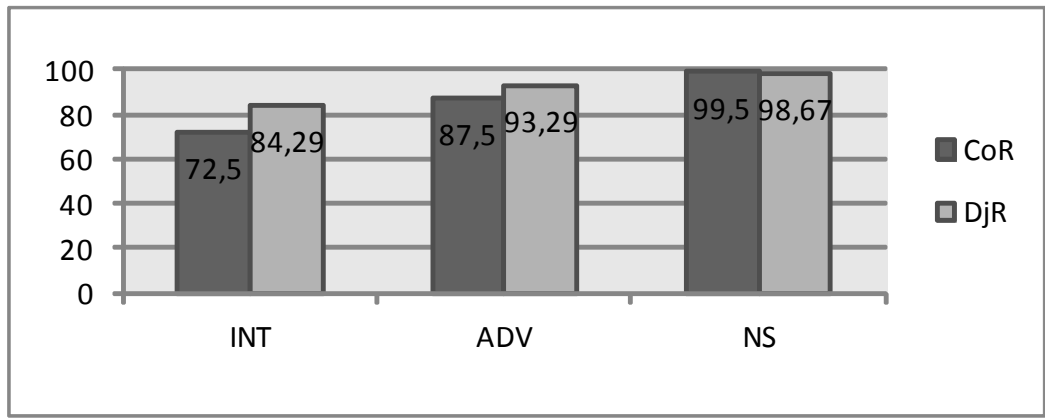

Figure 5. Pronominal Subject Use: CoR vs. DjR

These scores reveal that the L2 groups produce more null subject pronouns in cases of coreference than of disjoint reference. However, this tendency did not reach significance (both $p s>0.05$ ). In contrast, the controls produce overt subject pronouns irrespective of reference type $(p>0.05)$.

\subsubsection{Greek Test}

First, the results of the -WKI items of the test will be presented. See Figure 6.

The statistical analysis showed that there is a main effect of the PT variable (i.e. overt /null realization of pronoun) on the response $\left(\chi^{2}=206.481, \mathrm{df}=2, p\right.$ $<0.0001)$. When the subject pronoun is null, participants significantly favor the first-clause subject over the 'object' and 'either' options. By contrast, when the subject pronoun is overt, the object antecedent is preferred over the 'subject' and 'either' options at a significant rate. These findings show that in the absence of other factors Greek speakers resolve pronominal ambiguity based on the semantic properties related to the parametric option of null subjects in Greek; null pronouns are assigned to the most prominent antecedent, the first-clause subject, while overt pronouns are assigned to the first-clause object, as expected. 


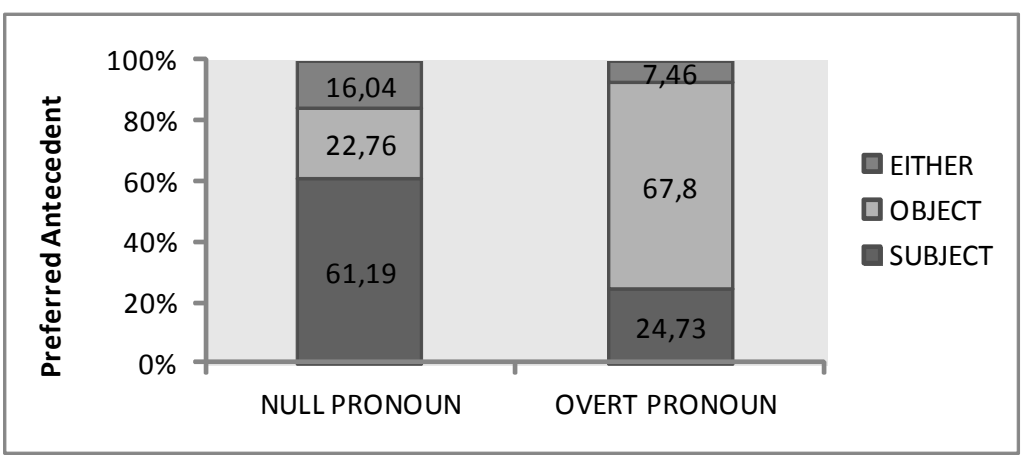

Figure 6. Responses in -WKI items

Next we will present the results from the +WKI items. Figures 7 and 8 provide responses in the subject and object biased items of the test respectively:

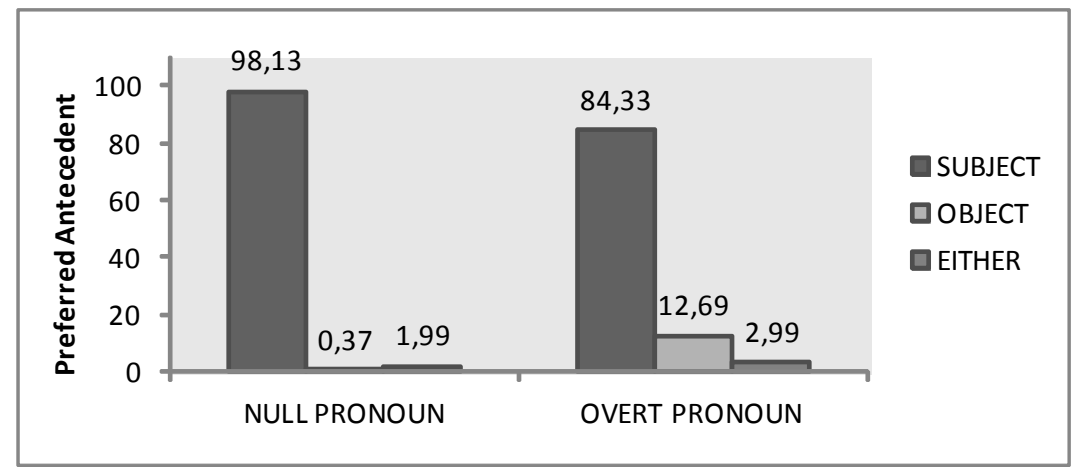

Figure 7. Responses in Subject Biased Items

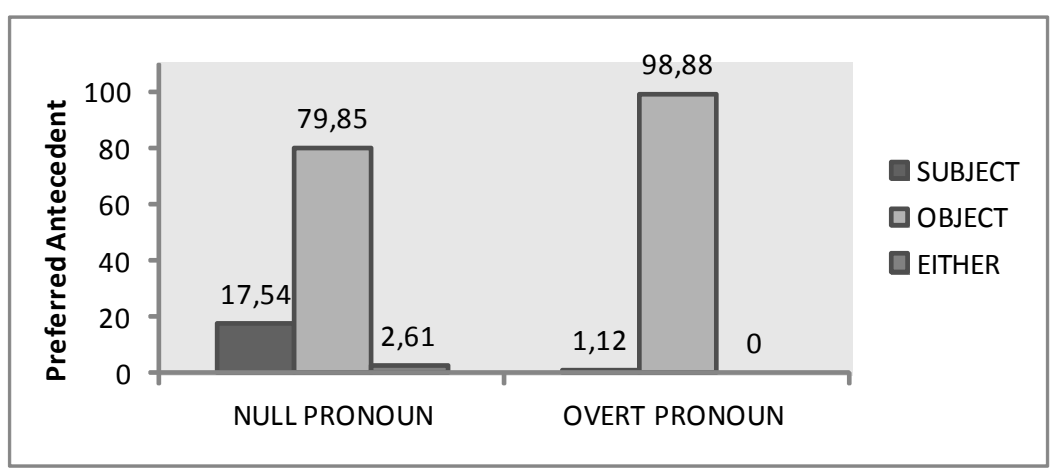

Figure 8. Responses in Object Biased Items 
The analysis showed a main effect of the variable of WKI on the response $\left(\chi^{2}=\right.$ $742.402, \mathrm{df}=2, p<0.001$ ). Greek speakers conform to the pragmatic constraints incorporated in the items and respond accordingly: in the subject biased items they overwhelmingly give a subject response (see Figure 7) while in the object biased items they clearly opt for the object antecedent (see Figure 8). Interestingly though, the analysis also indicated a main effect of the variable of PT on participant preferences $\left(\chi^{2}=26.374, \mathrm{df}=2, p<0.001\right)$, as well as a significant interaction of the variables involved (Wald test $=231$. 012, $p<0.001$ ). Multinomial regression tests applied to further examine all the possible differences resulting from this interaction showed that the responses given in the subject biased items and in the object biased items differed significantly with respect to the ratio of overt/null items (Wald test $=5.716, p<0.05$ ). This means that despite the preponderance of the subject responses in the subject biased type and of the object responses in the object biased type, the type of pronominal subject (overt/null) inflicted statistically significant distinct preference rates: in the subject biased type the subject response was favored significantly more when the pronoun to be referenced was null than when it was overt $(p<0.05)$. Accordingly, in the object biased items the object response was opted for at a significantly higher rate when the pronoun to be referenced was overt than null $(p<0.05)$. These results are remarkable because they show that although the variable of PT may not override that of WKI, the syntactic constraint related to the occurrence of null and overt subject pronoun variants in Greek is such a decisive factor in pronoun resolution that its effect surfaces even when pragmatic bias is involved.

\section{Discussion}

Starting with the acquisition of English pronominal subjects, it was predicted that due to the involvement of parameterized formal features, the L1 syntactic option of null pronominal subjects will be active in L2 grammars even in advanced stages of proficiency. Overall scores from all tasks have verified this prediction: not only INT but ADV learners as well accept/produce significantly more null pronominal subjects than the controls.

However, studies by Liceras Diaz \& Maxwell (1999) and Belletti et al. (2007) report that the production of null pronominal subjects in the L2 acquisition of NSLs by speakers of NNSLs was not distinguishable from that of the controls. Two points can be made on that: First, the direction of acquisition (i.e. acquisition of a null form when the L1 has only overt forms or acquisition of an overt form when L1 has null and overt forms) may involve different levels of difficulty (see Parodi \& Tsimpli, 2005). Second, these studies used only production tests, while our experiment used both judgement and production tasks, which may have affected results. 
Returning to our study, the obtained data allows us to assume that parameterized uninterpretable features related to the obligatorily overt manifestation of English subjects are inaccessible in adult L2 acquisition. For this reason, L2 learners transfer the L1 option of null pronominal subjects in developing and advanced L2 grammars. Based on that, it can be argued that accounts like the Interpretability Hypothesis which propose that uninterpretable features are not acquirable in adult $L 2$ acquisition are supported by our data.

Moving on to interpretation, it was hypothesized that L2 learners but not the NS will accept/produce more null pronominal subjects when these refer to the first-clause subject than when they are referentially disjoint from it, transferring an L1 property. Data from the PGJT and the SCT support this hypothesis. Findings from the $\mathrm{CT}$ attest only a tendency towards that direction. This could stem from the fact that the $\mathrm{CT}$ is a more demanding task as test items were presented in short texts the meaning of which participants had to grasp in order to complete the task. The case might be that participants were more reluctant to omit subject pronouns.

Given the above, we can maintain that the parametric choice of null subjects which, as previously discussed, appears to be active in $L 2$ grammars, seems to be exploited by Greek learners to encode interpretative effects in the interlanguage system exactly in the way implemented in L1: null pronominal subjects in topiccontinuity, overt pronominal subjects in topic-shift. In other words, the semantic distinctions made possible by the syntax of pro-drop (i.e. null pronouns denoting topic-continuity) are enforced in interlanguage systems as L2 learners resort to L1 syntactic options in structures where uninterpretable features are involved. Consequently, it can be claimed that the transfer of L1 parameterized options in L2 acquisition could be responsible for the attested optionality in pronominal subject realization. Given that the interpretable feature of [topic-shift] exploits a parametric option, residual optionality in pronominal subject realization cannot be viewed in isolation from the consistent pattern of unsuccessful L2 performance evinced through the overall use of null pronominal subjects in the English tests. Therefore, the assumptions of Interface Vulnerability Hypotheses according to which variability at the syntax-discourse is unrelated with formal features but attributed to a problem with interpretable features are questioned by our findings.

Turning to the Greek Test, results have shown that the contrasts in reference assignment related to the Pronoun Type variable are detected not only in the non-biased items, as expected, but also in the biased items, which is rather interesting. In the non-biased items, data on the assignment of null pronominal subjects to the subject of the first clause allow us to strongly claim that Greek learners drop subject pronouns in English subordinate clauses because they interpret them as coreferential with the first-clause, which shows transfer of an L1 strategy. In the biased items on the other hand, antecedent preferences were 
clearly determined by inferences based on world knowledge, yet null pronouns were found to favor more subject antecedents and overt pronouns to choose more object antecedents within the subtypes of subject and object biased items respectively. This shows that assignment of pronominal reference in Greek is resolutely affected by the syntactic constraint associated with the null/over manifestation of the pronoun, even in the presence of factors like pragmatic bias.

On the whole, our data seem to suggest that syntax and the semantic distinctions encoded by parametric choices are crucial both in L2 pronominal subject interpretation and use, as well as in the $L 1$ resolution of pronoun ambiguity in NSLs like Greek. This implies that in the examination of L2 pronominal use and interpretation the factor of cross-linguistic influence not only is relevant but, probably, should be considered first, over factors which have to do with the interface status of the phenomenon or the executive functions involved. 


\section{References}

Alexiadou, A. and E. Anagnostopoulou. 1998. Parametrizing agr: word order, V-movement and EPP-checking. Natural Language and Linguistic Theory 16(3): 491-539.

Alonso-Ovalle, L., S. Fernández-Solera, L. Frazier and C. Clifton. 2002. Null vs. Overt Pronouns and the Topic-Focus Articulation in Spanish. Rivista di Linguistica, 14(2): 151-169.

Barbosa, P. 1995. Null Subjects. Ph.D Thesis, MIT.

Barbosa, P. 2009. Two kinds of subject Pro. Studia Linguistica 63(1):2-58.

Belletti, A., E. Bennati and A. Sorace. 2007. Theoretical and developmental issues in the syntax of subjects: evidence from near-native Italian. Natural Language and Linguistic Theory 25(4): 657-689.

Bini, M. 1993. La adquisición del italiano: más allá de las propiedades sintácticas del parámetro pro-drop. In J. Liceras (ed.), La lingüística y el análisis de los sistemas no natives. Ottawa: Dovehouse, 129-139.

Cardinaletti, A. and M. Starke. 2001. The typology of structural deficiency. In $\mathrm{H}$. van Riemsddijk (ed.), Clitics in the languages of Europe, Vol. 8 of Language Typology. Berlin: Mouton de Gruyter.

Carminati, M.-N. 2002. The Processing of Italian Subject Pronouns. Ph.D Thesis, University of Massachusetts Amherst.

Carminati, M.-N. 2005. Processing reflexes of the Feature Hierarchy (Person>Number>Gender) and implications for linguistic hierarchy. Lingua 115(3): 259-285. 
Chomsky, N. 1995. The Minimalist Program. Cambridge, MA:, MIT Press.

Chomsky, N. 2001. Derivation by phase. In M. Kenstowicz (ed.), Ken Hale: A life in language. Cambridge, MA: MIT Press.

Dimitriadis, A. 1996. When pro-drop languages don't: Overt pronominal subjects and pragmatic inference. In Proceedings of the 32 nd Meeting of the Chicago Linguistics Society. Chicago, 33-47.

Geber, D. 2006. Processing Subject Pronouns in Relation to Non-canonical (Quirky) Constructions. Ottawa Papers in Linguistics 34: 47-61.

Hawkins, R. and H. Hattori. 2006. Interpretation of English multiple wh-questions by Japanese speakers: a missing uninterpretable feature. Second Language Research 22(3): 269-301.

Hulk, A. and N. Müller. 2000. Bilingual first language acquisition at the interface between syntax and pragmatics. Bilingualism: Language and Cognition 3(3): 227-244.

Jegerski, J., B. Van Patten and G. Keating. 2011. Cross-linguistic variation and the acquisition of pronominal subject reference in L2 Spanish. Second Language Research 27(3): 482-507

Liceras, J., L. Diaz and D. Maxwell. 1999. Null arguments in non-native grammars: the Spanish L2 of Chinese, English, French, German, Japanese and Korean speakers. In E. Klein and G. Martohardjono (eds.) The development of second language grammars: A generative approach. Amsterdam: John Benjamins, 109145.

Lozano, C. 2008. Selective deficits at the syntax-discourse interface: Evidence from the CEDEL2 corpus. In N. Snape, Y.-k.I. Leung and M. Sharwood-Smith (eds.), Representational Deficits in SLA. Amsterdam: John Benjamins, 127-166.

Lozano, C. 2009. Pronominal deficits at the interface: new data from the CEDEL2 corpus. In C.M. Bretones Callejas et al. (eds.), Applied Linguistics Now: Understanding Language and Mind/La Lingüística Aplicada Hoy: Comprendiendo el Lenguaje y la Mente. Almería: Universidad de Almería, 213-227.

Margaza, P. and A. Bel. 2006. Null subjects at the syntax-pragmatics interface: Evidence from Spanish interlanguage of Greek speakers. In M. Gratham O'Brien, C. Shea and J. Archibald (eds.), Proceedings of GASLA 2006. Somerville, MA: Cascadilla Press, 88-97. 
Meridor, H. 2006. An Experimental Investigation of the Antecedent Preferences of Hebrew Subject Pronouns, MA Dissertation, University of Edinburgh.

Miltsakaki, E. 2007. A rethink of the relationship between salience and Anaphora Resolution. In Proceedings of the 6th Discourse Anaphora and Anaphor Resolution Colloquium. Lagos, Portugal.

Montrul, S. and C. Rodríguez Louro. 2006. Beyond the syntax of the Null Subject Parameter: A look at the discourse-pragmatic distribution of null and overt subjects by L2 learners of Spanish. In V. Torrens and L. Escobar (ed.). The Acquisition of Syntax in Romance Languages. Amsterdam: John Benjamins, 401418.

Oxford Quick Placement Test 2001, version 1. UCLES 2001

Papadopoulou, D., E. Plemenou, T. Marinis and I.-M. Tsimpli. 2007. Pronoun ambiguity resolution: evidence from L1 Greek children. Clinical Language Sciences, University of Reading.

Pérez-Leroux, A. and W. Glass. 1999. Null anaphora in Spanish second language acquisition: probabilistic versus generative approaches. Second Language Research 15(2): 220-249.

Parodi, T. and I.-M. Tsimpli. 2005. 'Real' and apparent optionality in second language grammars: finiteness and pronouns in null operator structures. Second Language Research 21(3): 250-285.

Roussou, A. and I.-M. Tsimpli. 2006. On Greek VSO again! Journal of Linguistics 42(2): 317-354.

Smith, N. and I.-M. Tsimpli. 1995. The mind of a savant. Language Learning and Modularity. Oxford: Blackwell.

Sorace, A. and F. Filiaci. 2006. Anaphora resolution in near-native speakers of Italian. Second Language Research 22(3): 339-368.

Sorace, A. and L. Serratrice. 2009. Internal and external interfaces in bilingual language development: Beyond structural overlap. International Journal of Bilingualism 13(2): 195-210.

Spyropoulos, V. and I. Philippaki-Warburton. 2001. Subject and EPP in Greek: the discontinuous subject hypothesis. Journal of Greek Linguistics 2: 149-186. 
Tsimpli, I.-M. and M. Dimitrakopoulou. 2007. The Interpretability Hypothesis: evidence from wh-interrogatives in second language acquisition. Second Language Research 23(2): 215-242.

Tsimpli, I.-M., A. Sorace, C. Heycock and F. Filiaci. 2004. First Language Attrition and Syntactic Subjects: A Study of Greek and Italian Near-Native Speakers of English. International Journal of Bilingualism 8(3): 257-277.

Tsimpli, I.-M., A. Sorace, C. Heycock, F. Filiaci and M. Bouba. 2003. Subjects in L1 attrition: Evidence from Greek and Italian Near-Native Speakers of English. In B. Beachley et al. (eds.), BUCLD 27 Proceedings, 787-797. 